Florian Part, Sabine Greßler, Marion Huber-Humer, André Gazsó*

\section{Environmentally relevant aspects of nanomaterials at the end of the use phase - Part I: Wastewater and sewage sludge}

\section{Summary}

Synthetically produced nanomaterials (Engineered Nanomaterials - ENMs) can potentially be released along the entire lifecycle of a product. The use of products with suspended ENMs, such as sunscreen lotions, almost certainly leads to an immediate environmental input. In contrast, ENMs that are solidly integrated in a product matrix can only be released by mechanical and/or chemical processes. ENMs can enter the environment either directly or indirectly (e.g. during the disposal phase), where both their properties and environmental conditions can determine their aggregation behavior. Weathering experiments with facade paints show that only a very small proportion of the contained titanium dioxide nanoparticles $\left(\mathrm{TiO}_{2}-\mathrm{NPs}\right)$ are released. In paints with silver nanoparticles (Ag-NPs), however, up to $30 \%$ of the particles can leach out over time. In the case of textiles treated with Ag-NPs, up to $10 \%$ of the silver contents can be washed out and enter the wastewater. Tests show that Ag-NPs can be transported over long distances in sewers without deposition. These are partly transformed into water-insoluble silver sulfide. Up to $85 \%$ of the $\mathrm{TiO}_{2}-\mathrm{NPs}$ and up to $99 \%$ of the Ag-NPs are removed via sewage sludge during wastewater treatment, whereby Ag-NPs and other silver forms are transformed into water-insoluble silver chloride and -sulfide. Once ENMs enter surface waters, a differentiation between natural and engineered nanoparticles becomes complicated. Studies on $\mathrm{TiO}_{2}-\mathrm{NPs}$, which can enter swimming waters via sunscreen lotions, show that these aggregate quickly and can subsequently be measured in the sediment.

\section{Introduction}

The applications of engineered nanomaterials (ENMs) in products are manifold and have already been discussed in greater detail in earlier NanoTrust Dossiers. The precautionary principle and sustainability call for assessing the potential risks of ENMs. With regard to the dose and amount to which humans and the environment can be exposed, the decisive factor is how ENMs have been worked into the products. Hansen et al. ${ }^{1}$ call for principally distinguishing whether ENMs in a product are solidly integrated in a matrix, adhere to a surface or are present in suspended form. ENMs can potentially be released along the entire product lifecycle. The use of products with suspended ENMs, such as sunscreens, very probably leads to a direct input into the environment (for example by being washed off while swimming or when washing towels). In contrast, those ENMs contained in sports equipment can be released only by mechanical and/or chemical processes (e.g. shredding processes during recycling or during waste incineration) ${ }^{2}$. Any evaluation of potential environmental impacts requires knowing and determining the form or chemical species along with the concentration of ENMs in environmental media. If nanomaterials are released intentionally or accidentally into the environment during or at the end of their use phase, then the properties of the nanoparticles as well as the prevailing environmental conditions determine whether and how quickly particles pass into solution or form stable aggregates/agglomerates. The behavior and mobility of nanomaterials in the environment depend above all on the so-called colloidal stability of the particles (see also ${ }^{3}$ ).

Figure 1:

Nano-objects in an unstable colloidal system - Nanoparticles, -fibers and -plates unite into larger aggregates/agglomerates and precipitate out or flocculate. ${ }^{5}$
Fundamentally, a colloidal system consists of a disperse phase and a dispersion medium. Accordingly, the dispersed titanium dioxide nanoparticles $\left(\mathrm{TiO}_{2}\right.$-NPs) (suspensions) in sunscreens for example or catalysts made of cerium dioxide nanoparticles $\left(\mathrm{CeO}_{2}-\mathrm{NPs}\right)$, which are distributed in the air (aerosols), represent a colloid system. Regarding colloidally stable nanoparticles the aggregation of particles is hindered largely by their surface properties - due to a specific surface charge or steric effects. Such nanoparticles remain dispersed - stable and mobile - in the environmental medium. In contrast, colloidally unstable nanoparticles aggregate with one another or with other colloidal particles (homo- and hetero-aggregation). This leads to a socalled two-phase separation, whereby aggregates sediment or flocculate due to gravity or buoyancy (Figure 1). This is the principle behind the removal of pollutants in the biological purification stage of a sewage treatment plant. The resulting sludge, which can potentially also contain ENMs, then subsequently undergoes further waste management treatment (biological and/or thermal stabilization processes) or is directly applied as agricultural fertilizer. A separate NanoTrust Dossier ${ }^{4}$ provides an overview of the general issue "nanowaste". The present dossier focuses on the issues "wastewater" and "sewage sludge".

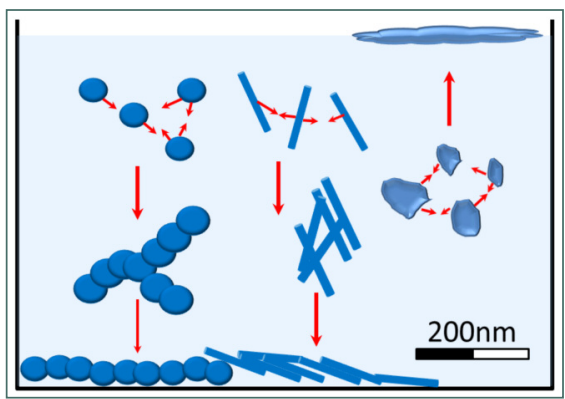




\section{Potential input of ENMs in urban wastewater systems and surface waters}

Many ENMs, such as nano-scale metals and metal oxides, are incorporated into a product as additives and are thus integrated in its matrix. The risk of any release during the use phase is considered to be minimal. In contrast, the potential release of those ENMs that are contained in cosmetics is estimated to be much higher ${ }^{6}$. Thus, ENMs can enter surface waters, the groundwater or soil either directly or indirectly via the urban wastewater system as well as via waste management processes and facilities (Figure 2).

Various physical and chemical processes can unintentionally release ENMs into the environment. For example, $\mathrm{TiO}_{2}-\mathrm{NPs}$ in sunscreens can be washed off into swimming waters or pools (direct input). The environmental input of $\mathrm{TiO}_{2}-\mathrm{NPs}$ contained in house paints or construction materials can occur during the use phase through weathering processes and during the disposal phase through abrasion in recycling facilities for construction and demolition wastes or through leaching processes in a landfill (indirect input). Washing can leach nanosilver (Ag-NPs) from the product matrix of textiles, and transforming Ag-NPs into other chemical compounds during transport in wastewater systems and at various waste management steps (from wastewater treatment to sewage sludge treatment and disposal) (formation of new chemical species).

A Swiss research team conducted long-term studies on the potential release of $\mathrm{TiO}_{2}-\mathrm{NPs}$ and larger $\mathrm{TiO}_{2}$-pigments used as additives in wall paints ${ }^{8}$. The commercially available paints were applied to small panels made of fiber cement and expanded polystyrene. Weathering effects and exposure to sunlight were then simulated in climate chambers. The panels were examined with regard to the effect of pure-, tap- and rainwater as well as UV-light. These experiments were conducted not only under laboratory conditions but also under real outdoor conditions (3-week exposure). Moreover, aging of the paints was artificially simulated through mechanical shredding processes and UV-A irradiation. After 113 test cycles the weathering experiments showed that a mere $0.007 \%$ of the $\mathrm{TiO}_{2}-\mathrm{NPs}$ incorporated in the paints was released. From these results, Al-Kattan et al. ${ }^{8}$ conclude that $\mathrm{TiO}_{2}-\mathrm{NPs}$ in the paints remains present in bonded form. After the samples were artificially aged - initially by UV-light and then by grinding - the amount of released ENMs rose 100-fold. Those paints that contained only larger $\mathrm{TiO}_{2}$-pigments rather than $\mathrm{TiO}_{2}-\mathrm{NPs}$ showed no such increase during the aging process. The authors attribute this effect to the addition of $\mathrm{TiO}_{2}-\mathrm{NPs}$ as well as to the photocatalytic decomposition of the organic pigment matrix.

Another study ${ }^{9}$ simulated the loss of $\mathrm{TiO}_{2}$ NPs through the mechanical cleaning of facades. Here, hardened paint surfaces containing $\mathrm{TiO}_{2}-\mathrm{NPs}$ or no ENMs were treated for a predefined periods by sandblasting. The toxicity of the residues was examined based on in-vitro experiments with mice. The toxicity of dusts from the sandblasting treatment with $\mathrm{TiO}_{2}-\mathrm{NPs}$ was not higher than that of dusts without ENMs.

The effect of various weathering factors in releasing Ag-NPs from the outside walls of a model house was examined over a period of 372 days in the framework of a Swiss study ${ }^{10}$. The results showed that about $30 \%$ of the Ag-NPs applied in the paint was washed out during the study period. The largest amounts of ENMs were already washed out from the pigment matrix during the first 8 rain events. After about 180 days, a silver concentration in the lower ppb-range (ca. $1 \mu \mathrm{g} / \mathrm{L}$ ) was measured in the rainwater drains. The detected Ag-NPs were mostly in the size range of less than $15 \mathrm{~nm}$ and adhered to the organic binding agent of the paint. Transmission electron microscopy (TEM) revealed aggregates consisting of several Ag-NPs.

ENMs that enter the communal wastewater system via rainwater drains can be affected or transformed by the prevailing environmental conditions.

\section{How do ENMs behave in wastewater?}

A Swiss study ${ }^{11}$ dealt with the behavior of silver in washing water. Silver is applied as an additive to textiles due to its antibacterial effect and can potentially be washed out. The textiles contained different forms of silver including silver chloride $(\mathrm{AgCl})$, silver zeolite (Ag-Z) and nanoparticulate silver (Ag-NPs). The washing experiments were conducted at $40^{\circ} \mathrm{C}$ using a standardized detergent. During these experiments, up to ca. $34 \%$ of the total amount of silver incorporated in die textiles were washed out from those textiles with conventional additives ("non-nano"), whereas the value for those textiles with Ag-NPs was up to $10 \%$. This demonstrated that textiles with Ag-NPs released less silver than textiles with conventional additives comprising $\mathrm{AgCl}$ and $\mathrm{Ag}-\mathrm{Z}$ ("non-nano"). The released silver was present in the wash water in dissolved form as silver ions $\left(\mathrm{Ag}^{+}\right)$, nanoparticulate silver and largely as silver chloride (note: $\mathrm{AgCl}$ is practically insoluble in water and immediately precipitates as a white deposit). Remarkably, silver was washed out of the conventionally treated textiles (without $\mathrm{Ag}-\mathrm{NPs}$ ), and this silver was subsequently transformed into nanoparticulate silver. Accordingly, Ag-NPs were recorded in all wastewater samples. Mitrano et al. ${ }^{11}$ assumed that in the initial washing phase, mostly ionic along with nanoparticulate silver forms $\left(\mathrm{Ag}^{+}\right.$ or Ag-NP) were present, which transformed after a period of time and thus partially led to new formation of Ag-NPs.

Figure 2: Schematic overview of the various input pathways of ENMs with a focus on urban wastewater systems after Duester et al. ${ }^{7}$ Wastewater, heavy rain overflows and sewage treatment plants represent significant "transitio compartments". Sewage sludges, surface waters, soils and groundwater serve as potential "end compartments". Disposal sites or cement construction material with sewage sludge or ash additives from sludge incineration can also be "end compartments".

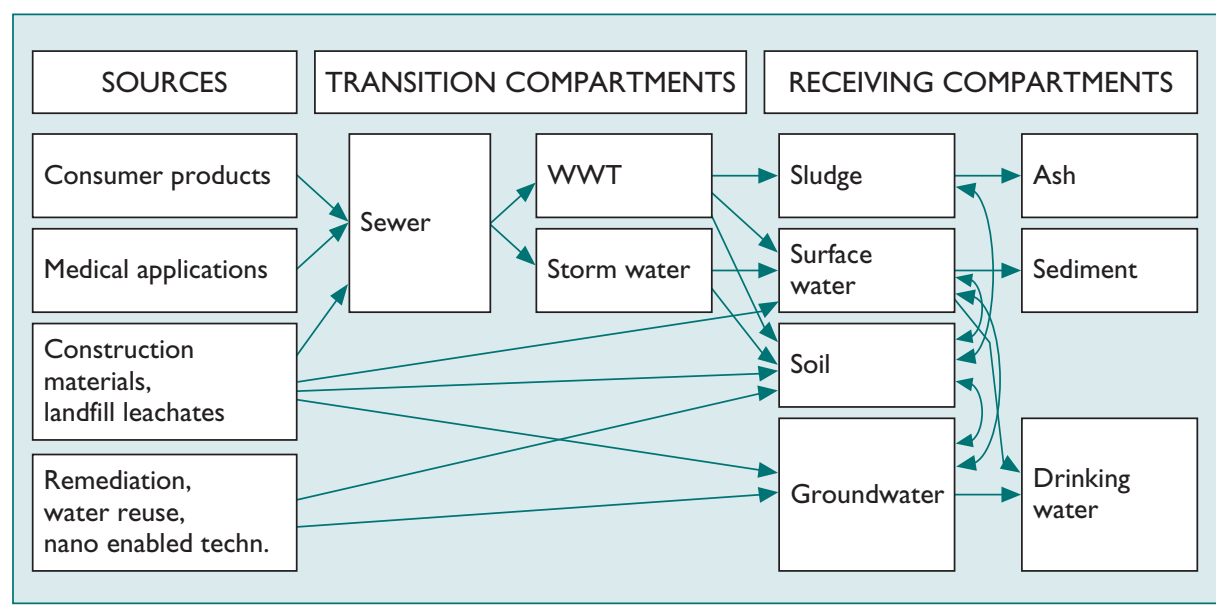


Kaegi et al. ${ }^{12}$ examined the transport behavior of Ag-NPs along a 5-km-long experimental sewer and analyzed 40 water samples. Ag-NPs were transported along this sewer without significant deposition and therefore reached the wastewater treatment plant. Along this sewage tunnel, the authors were unable to detect any negative effects on the biofilm that develops in pipelines. This study also considered potential transformation processes of Ag-NPs. Based on additional laboratory experiments, the authors determined that Ag-NPs partially transformed in water-insoluble silver sulfide $\left(\mathrm{Ag}_{2} \mathrm{~S}\right)$ because the wastewater contained the sulfur necessary to form these compounds.

\section{What happens with ENMs during wastewater treatment?}

Kiser et al. ${ }^{15}$ examined several wastewater treatment plants in the USA to determine the fate of $\mathrm{TiO}_{2}-\mathrm{NPs}$. The authors collected water samples from the sewage plant effluent at various times as well as sewage sludge samples from the primary and secondary clarifier (Figure 4). $\mathrm{TiO}_{2}$-NPs were added to these samples to analyze their behavior. This effort was accompanied by using a laboratory experimental reactor in order to simulate aeration- and sedimentation processes during biological treatment. Analytic methods such as optical emission spectrometry
(ICP-OES) and scanning electron microscopy (SEM) ${ }^{16}$ were used to quantitatively and qualitatively evaluate the $\mathrm{TiO}_{2}-\mathrm{NP}$-emissions. The lab studies showed that 70 to $85 \%$ of the added $\mathrm{TiO}_{2}-\mathrm{NPs}$ was accumulated in plant solids; this was confirmed in field studies. The authors concluded that most of the $\mathrm{TiO}_{2}-\mathrm{NPs}$ can be removed from the wastewater via the sewage sludge.

Sewage sludges can therefore represent a significant sink for $\mathrm{TiO}_{2}$-NPs. In many countries the sludges are directly applied to agricultural surfaces to utilize the nutrients (phosphorus and nitrogen), although thermal or biotechnical treatments are also available. Kiser el al. ${ }^{15}$ point out that these results are not transferable to other ENMs with different density, surface coatings or other physico-chemical properties.

Impellitteri et al. ${ }^{17}$ examined the chemical transformation of Ag-NPs during wastewater treatment. In a pilot wastewater treatment plant with primary-, activated sludge- and secondary basins and clarifiers, Ag-NPs were added to the inflow. During these studies less than $3 \%$ of the total Ag-NPs could be measured in the overflow of the primary clarifier. The authors therefore assumed that $97 \%$ of the applied Ag-NPs can be removed by sedimentation (the Ag-NPs in the sewage sludge were present both in bound and in suspended form). The treatment plant outflow contained less than $1 \%$ of the Ag-NPs. The conclusion was that, overall, more than $99 \%$ can be removed via sewage sludge. The behavior of the various silver species was also examined in more detail. Here, Ag-NPs

\section{Collection of municipal wastewater in Austria:}

Facade- or rainwater drainage systems are largely collected and treated in wastewater treatment plants. In Austria the current level of connection to canalization is very high (over $90 \%)^{13}$. In Austria, diffuse input of ENMs (without wastewater treatment) is largely restricted to extreme events when overflows of the mixed water- or drinking water canalization are activated (for example during floods). Those $10 \%$ of Austrian households that are not connected to the municipal wastewater collection system (e.g. in high alpine regions) can potentially also contribute to a diffuse, direct input of ENMs into the environment.

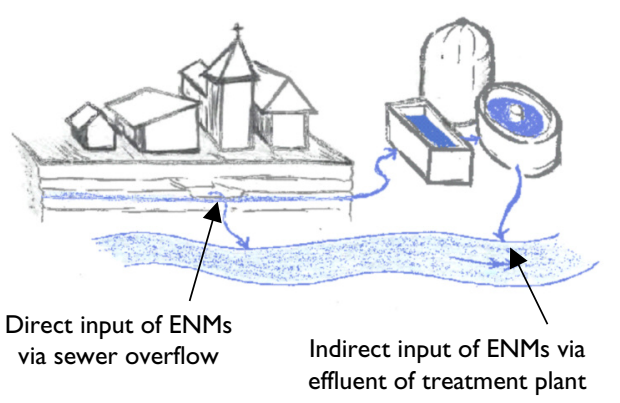

Figure 3:

Schematic representation of a mixed water system for wastewater collection. ENM can potentially enter the surface waters directly (via sewer overflow) or indirectly (after wastewater treatment). ${ }^{14}$ with silver sulfide $\left(\mathrm{Ag}_{2} \mathrm{~S}\right)$ and silver nitrate $\left(\mathrm{AgNO}_{3}\right)$ were experimentally compared in fresh and artificially aged sewage sludge samples as well as under well-oxygenated and oxygen-poor conditions. The analyses of the fresh versus aged sludges showed that the silver was present largely as silver sulfide $\left(\mathrm{Ag}_{2} \mathrm{~S}\right)$, but also other silver compounds and complexes were formed. The silver content in the sludges that were incinerated at $850^{\circ} \mathrm{C}$ was largely composed of silver sulfate $\left(\mathrm{Ag}_{2} \mathrm{SO}_{4}\right)$ under atmospheric oxygen conditions. These samples also contained small amounts of silver complexes and isolated fragments of elemental silver $\left(\mathrm{Ag}^{0}\right)$, whose formation depends primarily on the retention time and temperature during the incineration process.

Overall, Ag-NPs tend to aggregate to larger particles during wastewater treatment. These studies, however, were not designed to more closely examine the colloidal stability of the Ag-NPs. Impellitteri et al. ${ }^{17}$ underline that the potential transformation processes of ENMs that occur in various environmental media should be considered in lifecycle analyses (LCA).

A Swiss study ${ }^{18}$ at a pilot wastewater treatment plant as well as at two operational treatment plants yielded similar results. In both cases, more than $95 \%$ of the silver loads could be eliminated through adsorption onto activated sludge floccules that form during the biological treatment stage. In operational treatment plants the elimination rate could be increased up to $99 \%$ by additionally deploying sand filters in the outflow of the biological treatment stage. The authors conclude that virtually no free silver ions $\left(\mathrm{Ag}^{+}\right)$ are present and that Ag-NPs along with other silver compounds are transformed into water-insoluble silver chloride $(\mathrm{AgCl})$ and -sulfide $\left(\mathrm{Ag}_{2} \mathrm{~S}\right)$. The experiments at the pilot plant also showed no inhibition of ammonium decomposition by nitrifying bacteria at a relatively high silver dose of $1 \mathrm{mg} / \mathrm{L}$ (lower ppm-range) compared with the reference sample (without silver). Kaegi et al. ${ }^{12}$ also confirmed in the framework of their experiments that the elimination rate for $\mathrm{Ag}$ NPs - as well as for gold-NPs (Au-NPs) - is very high and that over $99 \%$ of the applied amount is precipitated via the sewage sludge. 


\section{What happens with ENMs in surface waters?}

NanoTrust Dossier ${ }^{3}$ summarized the potential processes that influence the behavior and properties of nanomaterials in the environment. Currently, analytical methods continve to be adapted and refined in order to properly monitor the ENM-input into environmental media and to analyze and evalvate their environmental behavior. For example, in the framework of a research project, water samples were taken from the Alte Donau (old Danube channel) in Vienna over the course of a year in order to measure the input of ENMs such as $\mathrm{TiO}_{2}-\mathrm{NPs}$ from sunscreen lotions ${ }^{22}$. The focus here was on the potential "mobile" ("suspended") fraction of $\mathrm{TiO}_{2}-\mathrm{NPs}$, which were sampled from the surface water at a depth of approx. $1 \mathrm{~m}$. In the summer months and at high visitor numbers a slight increase in the particle number concentration was measured. Nonetheless, the applied method (Single Particle ICP-MS) ${ }^{23}$ was unable to distinguish between manufactured (ENMs) and naturally present $\mathrm{TiO}_{2}-\mathrm{NPs}$ that stem from a variety of rock minerals.
Such a differentiation would require additionally determining the so-called element ratios. The underlying assumption is that the relationship between two elements, for example titanium and aluminum (Ti/Al), differs significantly in ENMs versus natural nanomaterials of similar composition. Accordingly, the above-mentioned study measured a slight increase in the element ratio (Ti/Al) in summer. In the autumn months this ratio sank again. The authors concluded that the residence time of $\mathrm{TiO}_{2}-\mathrm{NPs}_{\mathrm{s}}$ in the waterbody is relatively short and that these largely aggregate and sediment. Such an aggregation behavior was also determined under laboratory conditions and after considering the hydrochemistry of the Alte Donau. Gondikas et al. ${ }^{22}$ pointed out that $\mathrm{TiO}_{2}-\mathrm{NPs}$ can also be present in the organic, water-insoluble components of sunscreen lotions that accumulate on the water surface. The authors therefore call for additional investigations of this air-water interface as well as of the sediments.

A US research team ${ }^{24}$ studied the behavior of Ag-NPs with the goal of identifying the influence of hydrochemistry (dissolved organ- ic carbon, $\mathrm{pH}$ and water hardness) on the surface properties and size of Ag-NPs as well as on the solubility of silver ions $\left(\mathrm{Ag}^{+}\right)$. This involved mixing Ag-NPs with real water samples from the Watauga River (Tennessee) and then more closely examining their aggregation behavior as well as ecotoxicity. The toxicity of silver citrate (citrate-Ag-NPs), nitrate $\left(\mathrm{AgNO}_{3}\right)$ and free silver ions $\left(\mathrm{Ag}^{+}\right)$was investigated based on fecal bacteria (Escherichia coli). Under the prevailing test conditions, free $\mathrm{Ag}^{+}$-ions proved to be 16-times more toxic than citrate-Ag-NPs, whereby the latter was more toxic than $\mathrm{AgNO}_{3}$ by a factor of 44 . Increasing the $\mathrm{pH}$-value $(\mathrm{pH}>7)$ and the dissolved humic acid fraction reduced the toxicity of citrate-Ag-NPs for fecal bacteria.

Nonetheless, the toxicity increased as soon as the water hardness was increased. Moreover, the size of the citrate-Ag-NPs increased with increasing humic acid concentration and the size decreased with increasing water hardness. The authors thus again demonstrated that the prevailing water chemistry as well as the Ag-NP form (chemical species) play a key role in the colloidal stability and thus in the toxicity of these ENMs.

\section{Wastewater treatment and sewage sludge disposal in Switzerland and Austria:}

In Switzerland, no sewage sludge is permitted to be directly applied to agricultural surfaces since 2003. Subject to the legal transitional periods, more than $89 \%$ of the sewage sludge was treated in Swiss waste incineration plants in $2006^{20}$. In Austria, about $43 \%$ of the sludge were incinerated in 2010, with an addition $32 \%$ undergoing other treatment options (e.g.: composting or recycled in the brick industry) and $17 \%$ used agriculturally. Less than $8 \%$ of the sludge amount were directly dumped ${ }^{21}$. The trend is going toward a thermal treatment of sludge, so that the direct and indirect agricultural use (e.g. as fertilizer or compost) will continue to decrease. The reasons for this include public acceptance, strict legal requirements regarding hygiene and contaminant loads, as well as altered prerequisites in the certification of agricultural consumer products (e.g. specifications for quality labels). Nonetheless, in many other countries large amounts of sewage sludge continue to be directly applied on farmland (for example the entire sewage sludge of the city of Paris).

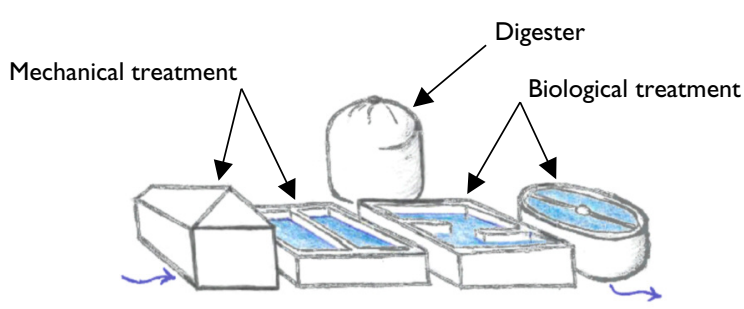

Figure 4:

Schematic representation of a wastewater treatment plant with sand trap basin and primary clarifier (mechanical treatment stage) along with activated sludge basin and secondary clarifier (biological treatment stage). In Austria, sewage sludges that accumulate during biological treatment are further managed as secondary wastes (e.g. incinerated or used agriculturally). ${ }^{19}$

\section{Conclusions}

Assessing the potential risk of engineered nanomaterials (ENMs) requires information on the exposure of humans and the environment. The decisive factor is the concentration and the manner how ENMs are incorporated in products. Principally, a low risk is assumed when ENMs are solidly integrated in a product matrix. If these compounds are present in suspended form, however, then an immediate direct or indirect input into the environment cannot be excluded. If ENMs enter wastewater, then sewage sludges can represent a significant "barrier". As sewage sludge is applied to agricultural surfaces in many countries, this issue deserves special attention. A direct input of ENMs into surface waters is also possible, for example through leaching from facade paints or via sunscreen lotions. Here, further studies are necessary, for example on the potential accumulation on the water surface (air-water interface) or in the sediment, because ENMs can aggregate and sediment depending on their properties and the environmental conditions. 


\section{Notes and References}

1 Hansen, Steffen Foss, et al., 2007, Categorization framework to aid hazard identification of nanomaterials, Nanotoxicology 1(3), 243-250; http://dx.doi.org/10.1080/ 17435390701727509

2 Petersen, Elijah J., et al., 2011 , Potential Release Pathways, Environmental Fate, And Ecological Risks of Carbon Nanotubes, Environ. Sci. Technol. 45(23), 9837-9856; http://dx.doi.org/10.1021/es201579y.

3 NanoTrust Dossier Nr. 027en.

${ }^{4}$ NanoTrust Dossier Nr. 040en.

${ }^{5}$ Figure prepared for this publication.

${ }^{6}$ EC (European Commission), 2012, Types and uses of nanomaterials, including safety aspects. Accompanying the Communication from the Commission to the European Parliament, the Council and the European Economic and Social Committee on the Second Regulatory Review on Nanomaterials. European Commission; http://ec.europa.eu/health/ nanotechnology/docs/swd_2012_288_en.pdf.

7 Duester, L., et al., 2014, Towards a comprehensive and realistic risk evaluation of engineered nanomaterials in the urban water system. Frontiers in Chemistry 2014, 2; http://dx.doi.org/10.3389/fchem.2014.00039.

${ }^{8}$ Al-Kattan, A. et al. (2013): Release of $\mathrm{TiO}_{2}$ from paints containing pigment- $\mathrm{TiO}_{2}$ or nano$\mathrm{TiO}_{2}$ by weathering. Environ Sci Process Impacts 15: 2186-93; http://dx.doi.org/10.1039/c3em00331k.

9 Saber, A. T., et al., 2012, Nanotitanium dioxide toxicity in mouse lung is reduced in sanding dust from paint. Part Fibre Toxicol 9: 4; http://dx.doi.org/10.1186/1743-8977-9-4.
10 Kaegi, Ralf, et al., 2010, Release of silver nanoparticles from outdoor facades, Environmental Pollution 158(9), 2900-2905; http://dx.doi.org/10.1016/j.envpol.2010.06.009.

11 Mitrano, Denise M., et al., 2014, Presence of Nanoparticles in Wash Water from Conventional Silver and Nano-silver Textiles, ACS Nano 8(7), 7208-7219; http://dx.doi.org/10.1021/nn502228w.

12 Kaegi, Ralf, et al., 2013, Fate and transformation of silver nanoparticles in urban wastewater systems. Water Research; http://dx.doi.org/10.1016/j.watres.2012.11.060.

13 ÖWAV, 2010: Regelblätter des Österreichischen Wasser- und Abfallwirtschaftsverbandes (ÖWAV). ÖWAV-Regelblatt 25. Abwasserentsorgung in dünn besiedelten Gebieten. 2., vollständig überarbeitete Auflage.

14 Figure prepared for this publication.

15 Kiser, M. A., et al., 2009, Titanium Nanomaterial Removal and Release from Wastewater Treatment Plants, Environmental Science \& Technology 43(17), 6757-6763; http://dx.doi.org/10.1021/es901102n.

16 ICP-OES: inductively coupled plasma optical emission spectrometry (e. g. for determination of concentration); SEM: scanning electron microscopy (e. g. for determination of particle size and shape).

17 Impellitteri, Christopher A., et al., 2013, Transformation of silver nanoparticles in fresh, aged, and incinerated biosolids, Water Research 47(12), 3878-3886 http://dx.doi.org/10.1016/i.watres.2012.12.041.

18 Burkhardt, M., et al., 2010, Verhalten von Nanosilber in Kläranlagen und dessen Einfluss auf die Nitrifikationsleistung in Belebtschlamm, Umweltwissenschaften und Schadstoff-Forschung 22(5), 529-540; http://dx.doi.org/ 10.1007/s12302-010-0153-2.

19 Figure prepared for this publication.
20 Originally cited: Bundesamt für Umwelt BAFU (2008): Klärschlamm: Mengenentwicklung und Entsorgungswege.

http://www.bafu.admin.ch/abfall/01472/ 01481/index.html? lang $=$ de\&download $=\mathrm{NH}$ zLpZeg7t,IENM6IONTU042I2Z6In 1 acy4Zn4Z2 qZpnO2Yuq2Z6gpJCFelN2gGym $162 \mathrm{epY}$ bg2c JjKbNoKSn6A-

[no longer available online, but numbers also published in: Bundesamt für Umwelt BAFU (2008): Abfallwirtschaftsbericht 2008. Zahlen und Entwicklungen der schweizerischen Abfallwirtschaft 2005-2007. p. 32

http://www.bafu.admin.ch/publikationen/ publikation/01009/index.html? lang=de].

21 Überreiter, E., Lenz K., Windhofer G., Zieritz, I., 2012, Kommunale Abwasserrichtlinie der EU -91/271/EWG, Österreichischer Bericht 2012, Bundesministerium für Land- und Forstwirtschaft, Umwelt und Wasserwirtschaft, Sektion VII; http://www.bmlfuw.gv.at/dms/lmat/ wasser/wasserqualitaet/abwasserreinigung/ Lagebericht 2012/Lagebericht-2012/ Lagebericht\%202012.pdf.

22 Gondikas, A. P., et al., 2014, Release of $\mathrm{TiO}_{2}$ Nanoparticles from Sunscreens into Surface Waters: A One-Year Survey at the Old Danube Recreational Lake, Environmental Science \& Technology 48(10), 5415-5422; http://dx.doi.org/10.1021/es405596y.

23 Single Particle ICP-OES: inductively coupled plasma optical emission spectrometry (e. g. for determination of concentration); SEM: scanning electron microscopy (e. g. for determination of particle size and shape).

24 Pokhrel, Lok R., et al., 2014, Natural water chemistry (dissolved organic carbon, $\mathrm{pH}$, and hardness) modulates colloidal stability, dissolution, and antimicrobial activity of citrate functionalized silver nanoparticles, Environmental Science: Nano 1(1), 45-54; http://dx.doi.org/10.1039/C3EN00017F.

\section{MASTHEAD:}

Owner: Austrian Academy of Sciences; legal person under public law (BGBI 569/1921; BGBI I 130/2003); Dr. Ignaz Seipel-Platz 2, A-1010 Vienna

Editor: Institute of Technology Assessment (ITA); Strohgasse 45/5, A-1030 Vienna; www.oeaw.ac.at/ita

Mode of publication: The NanoTrust Dossiers are published irregularly and contain the research results of the Institute of Technology Assessment in the framework of its research project NanoTrust. The Dossiers are made available to the public exclusively via the Internet portal "epub.oeaw" : epub.oeaw.ac.at/ita/nanotrust-dossiers

NanoTrust-Dossier No. 043en, February 2015 epub.oeaw.ac.at/ita/nanotrust-dossiers/dossier043en.pdf ISSN: 1998-7293 